\title{
A aprendizagem profissional da gestão de comportamentos na educação pré- escolar
}

\author{
Professional learning of behavior management in childhood education
}

\author{
Rosa Maria Ramos Novo, Ana Raquel Russo Prada \\ Departamento de Psicologia, Instituto Politécnico de Bragança, Escola Superior de Educação, Portugal
}

\begin{abstract}
Resumo
Este artigo identifica as semelhanças e diferenças na aprendizagem da gestão de comportamentos pelas educadoras-estagiárias de Educação de Infância. Para tal, no âmbito da prática pedagógica final, acompanharam-se dois contextos supervisivos com distintos modos de fazer pedagógico: transmissivo e de participação. O estudo seguiu uma abordagem de natureza descritiva e interpretativa através da triangulação de diferentes fontes de dados (filmagem, notas de campo e portefólio). Os resultados demonstram que a aprendizagem profissional é contextual e que as educadoras-estagiárias e os contextos são realidades indissociáveis, havendo interdependência e interatividade entre as aprendizagens profissionais das candidatas a educadoras e os contextos supervisivos.

Palavras-chave: Gestão de comportamentos, Educação Pré-Escolar, Prática supervisionada, Estagiários.
\end{abstract}

\begin{abstract}
This article aims to identify the similarities and differences in the learning of behavior management by pre-school teachers-trainees. To accomplish these goals, during the final teaching practice, two pedagogically differentiated supervised contexts were followed: a socio-constructivist and a traditional context. This study followed a descriptive and interpretive approach, based on the triangulation of multiple sources of data (video recording, field notes and portfolio). The results indicated that the professional learning is contextual, that teachers-trainees and contexts are inseparable and that there's an interdependence and interaction between the professional learning of behavior management and the contexts where supervision takes place.

Keywords Behavior Management, Childhood Education, Supervision training, Pre-school teacher trainees.
\end{abstract}

\section{Introdução}

Nas últimas décadas, a descoberta da pedagogia como tecido unitário no âmbito das propostas educativas é um movimento muito forte.

Antes de perguntar o porquê de tal movimento, convém referir que essa redescoberta não está eivada de saudosismo mas de um sentido profissional responsável que procura, na tessitura da cultura profissional, compreensões e realizações que enriqueçam as respostas que, no presente e no futuro, é necessário construir.

A centralidade conferida ao modo compreensivo de pensar e fazer o educativo, ao modo integrador do fazer do educador- estagiário e o do fazer das crianças, prendese com três razões principais. Em primeiro lugar com a importância central da educação para a realização do ser humano e a importância da educação precoce desde o nascimento aos seis anos, para a vida actual e futura das crianças (Shonkoff \& Meiseils, 2000; Spodek, 2002). Em segundo lugar, com o facto de se saber que o impacto desta educação só tem significado se for de qualidade (Schweinhart et al., 2005; Sylva, Melhuish, Sammons, Siraj-Blatchford, \& Taggarat, 2004). Em terceiro lugar, com o facto de a formação de professores ser uma variável central para a qualidade (Craveiro, 2007; Oliveira-Formosinho, 1998; Parente, 2004). Mais especificamente, acresce que, na última década, se acentuou cada vez mais que a qualidade na formação de educadores exige que esta se centre na aprendizagem reflexiva (Alarcão \& Canha, 2013; Shon, 1983; Zeichner, 1993) e crítica (Nóvoa, 1992; Oliveira-Formosinho, 2002, 2005) do quotidiano da profissão (Niza, 2007).

De facto, a aprendizagem profissional e o seu exercício só têm sentido no quadro do serviço social e educativo, estimulando as aprendizagens das crianças. Já Dewey (1971) chamou a atenção da necessidade pragmática de valorizar as ideias pelas suas realizações e consequências. Malaguzzi (1993) não aceita ideias que não gerem práticas, que, por sua vez, não enriqueçam as ideias (Edwards, Gandini, \& Forman, 1999; Hoyuelos, 2004).

A investigação aqui relatada pretende assim constituir um olhar mais pormenorizado sobre a gestão de comportamentos de crianças em idade pré-escolar pelas educadoras-estagiárias, em contexto de estágio final.

Em termos de estrutura, num primeiro momento contrastam-se os dois modos de fazer pedagógico (o transmissivo e o de participação) e a centralidade do exercício de poder pelo adulto face à criança. Se seguida, apresenta-se o estudo levado a cabo e finalmemte conclui-se salientando a interdependência e a interatividade entre as aprendizagens profissionais das candidatas a educadoras e os contextos supervisivos.

\section{Dois modos de fazer pedagógico: o transmissivo e o de participação}

Partindo de Oliveira-Formosinho (2007), um exercício que a herança pedagógica dos dois últimos séculos permite é o de contrastar os modos de fazer pedagógico: o modo de transmissão e o modo de participação. No modo transmissivo, o educador assume um papel de transmissor de conhecimentos, orientando-se por objetivos que visam a aquisição de capacidades académicas, a aceleração das aprendizagens e a 
compensação dos défices. Por sua vez a criança, percebida como um ser tendencialmente passivo, no que se refere ao currículo, segue as instruções e quase se limita a responder e a atuar em conformidade.

No modo de fazer pedagógico de participação, o educador é visto como facilitador das aprendizagens que orienta a ação educativa com base em objetivos que visam promover o desenvolvimento, estruturar e dar significado à experiência, bem como construir aprendizagens e fomentar, através da educação, uma sociedade mais justa e equitativa. Reclama, portanto, uma imagem de criança que fala da competência participativa e do direito a essa participação. É necessário conquistar em paralelo a participação da supervisora cooperante de modo ativo e participativo para a formação das educadoras-estagiárias e das crianças.

O propósito deste sucinto contraste é o tornar claro que a formação prática não implica transformar imagens de criança/adulto e processo de ensino-aprendizagem, meramente para renovar o discurso, mas, fundamentalmente, para recriar a formação prática. Isto exige, tal como refere Oliveira-Formosinho (2005) "construir referenciais partilhados entre [a instituição de formação] e o terreno (contextos cooperantes onde se desenvolve a prática pedagógica). Só assim as candidatas a educadoras podem experienciar no terreno uma pedagogia que valoriza e utiliza a voz da criança” (p.14). Partindo deste pressuposto é fundamental assegurar a qualidade do quotidiano educativo nos contextos supervisivos, promovendo a conceptualização teórica e a reflexão das práticas com base em gramáticas pedagógicas bem definidas e estimulando a criação de redes interinstitucionais que envolvam tanto os educadores no terreno, como as organizações onde estes atuam e os formadores do ensino superior (Formosinho, 2002; Formosinho \& Oliveira-Formosinho, 2008; Oliveira-Formosinho, 1998) .

\section{O papel do adulto na construção sociomoral da criança}

Diversos autores têm refletido sobre como o exercício de poder pelo adulto influencia o desenvolvimento sociomoral da criança. Concretamente, não é possível descurar o contributo central de Piaget (1984) para a transição da moralidade heterónoma à moralidade autónoma. Estas duas morais correspondem a dois tipos diferenciados de dinâmica interativa entre adulto e criança. A moralidade heterónoma baseia-se no respeito unilaleral: neste caso, as normas e as regras de funcionamento na sala de atividades são primordialmente determinadas pelo adulto que, por conseguinte, encaminha a criança para uma responsabilidade objetiva, bem como para uma obediência à autoridade pelo poder de coerção que possui. Contrariamente, uma dinâmica interativa fundadora da autonomia baseia-se na reciprocidade e no respeito mútuos. Deste modo, a autonomia da criança não aparece como afirmação de uma liberdade sem limites mas como uma liberdade comprometida no sentido em que obedece a convições internas relativas às necessidades de respeito e de igualdade mútuas. Para Piaget (1984) é central limitar a autoridade e a obediência ao adulto e permitir à criança experimentar e partilhar o poder e, assim, transitar do respeito unilateral para o respeito mútuo.

Em concordância com a abordagem socioconstrutivista desenvolvida por este autor, tem crescido nos últimos anos o interesse pela relevância da figura do educador no sentido da construção sociomoral da criança (DeVries \& Zan, 1998; Lino, 1996; Oliveira-Formosinho \& Araújo, 2004). Mais especificamente, para DeVries e Zan (1998) a relação entre o educador e a criança deve pautar-se pela primazia da reciprocidade e pela minimização de atitudes autoritárias, de forma a constituir experiências socioemocionais significativas e imprescindíveis para o desenvolvimento da criança.

\section{Questão e objetivos do estudo}

Neste enquadramento, o estudo procura dar resposta à seguinte questão: Será que as vivências das educadorasestagiárias da pedagogia transmissiva ou de participação influenciam o tipo de estratégias que utilizam na gestão do comportamento das crianças?

Com o desenvolvimento deste estudo pretendeu-se identificar as semelhanças e diferenças na aprendizagem da gestão de comportamentos de crianças pelas educadoras-estagiárias.

\section{Método}

Tendo em conta que no nosso país há uma diversidade de contextos formais de educação de infância, julgou-se conveniente não se limitar o objeto de estudo a um único caso. Em Stake (2009) e em função dos propósitos da investigação, encontra-se a designação de estudo de caso coletivo, quando se recorre a um estudo instrumental de dois ou mais casos, semelhantes ou distintos, para uma maior compreensão de dado tema. Assim, no âmbito deste estudo, foram selecionadas duas educadorasestagiárias, em contexto de estágio final, em dois contextos supervisivos: um da rede pública e outro da rede de solidariedade social, ambos do concelho de Braga. Estes contextos foram selecionados em função da orientação pedagógica adotada, com o intuito de favorecer a compreensão do fenómeno em estudo.

No contexto onde se desenvolve uma pedagogia de participação, o grupo de crianças da sala é constituída por 25 crianças, com idades compreendidas entre os 3 e os 6 anos de idade. $\mathrm{O}$ contexto que persegue uma pedagogia transmissiva é igualmente um grupo heterogéneo, constituído por 24 crianças, com idades compreendidas entre os 3 e os 6 anos de idade.

Tendo em conta as características da investigação, obteve-se o consentimento informado, sendo o processo de entrada e permanência para efeitos de investigação negociado segundo as normas protocoladas da investigação qualitativa.

No estudo de casos, o pesquisador tem diversas formas disponíveis para a recolha de materiais empíricos. No presente estudo, combinaram-se múltiplas fontes, especificamente, notas de campo (Bogdan \& Biklen, 1994), análise documental dos portefólios do practicum 
(Serrano, 2000) e filmagem. Nenhuma fonte única possui uma vantagem indiscutível sobre as outras, visto que as várias fontes são complementares e refletem uma tentativa de assegurar uma compreensão do fenómeno em estudo (Yin, 2003). Esta diversificação de "fontes de evidência” é, para Stake (2009), um princípio muito importante a seguir num estudo de caso.

\section{Análise e discussão de resultados}

Como se exemplifica na tabela 1 , a estagiária no contexto de pedagogia de transmissão, recorre à exclusão da atividade, como uma atitude punitiva, utilizando duas vias complementares. Por um lado, após a retirada da criança esta é sempre acompanhada do agente de autoridade (educador de Infância/ auxiliar de educação) e, por outro, procura, através do conversa individual, que as crianças compreendam a relação causal entre erro e castigo. Outra estratégia evidente é o recurso à ameaça como forma de regulação do comportamento.

Nesta sala, a estagiária mostra claramente uma pedagogia de submissão, centrada no exercicio da autoridade do adulto. Evidencia-se um apelo ao conformismo (Piaget, 1984) e uma construção baseada no constrangimento e na obediência da criança (Lourenço, 2002; Vieira \& Lino, 2007). A ausência de partilha de controlo do poder, entre as crianças e a estagiária, reflete-se na organização da sala, não sendo evidente um quadro de regras que pudesse reforçar o envolvimento da criança na socioregulação (OliveiraFormosinho \& Araújo, 2004; Oliveira-Formosinho \& Araújo, 2008).

Os resultados indiretos de tal situação são fáceis de compreender, bem como os seus efeitos imediatos: quando a moralidade se adquire do exterior, ela permanece heterónoma (Piaget, 1984).

Tabela 1.

Exemplos de estratégias utilizadas pela estagiária em contexto de pedagogia de transmissão.

\begin{tabular}{cc}
\hline Ilustração & Fonte \\
\hline
\end{tabular}

Durante o planeamento, duas crianças batem-se. A estagiária isola-as do grupo, sentando-as perto de uma mesa e solicita à auxiliar de educação que as supervisione enquanto continua o planeamento com as restantes.

Notas de campo

Estão três crianças de castigo na sala, sentadas na manta sob a supervisão da estagiária. Tinham de permanecer sentadas e caladas enquanto as restantes viam um filme noutra sala.

"uma das dificuldades estava diretamente relacionada com a gestão das crianças, nomeadamente com a resolução de conflitos interpessoais” (p. 18)

"aprecio positivamente a educadora por cativar as crianças para as atividades, através da expressão que impunha à sua linguagem e por não reforçar os eventuais conflitos que se faziam registar entre as crianças" (p.18)

Em pequeno grupo, uma criança deu uma bofetada a outra, ao que a estagiária responde "Vem para a minha beira, sentaste aqui ao meu lado". Enquanto ajuda a criança agredida a sentar-se perto de si, a outra conversa com o colega do lado. A estagiária então diz: "Enquanto os meninos não estiverem todos calados, ninguém faz o plano e vamos ficar todos aqui sentados.” A criança não liga, deita-se no chão com as pernas para o ar. Depois de acalmada, a criança é excluído do grupo.

Filmagem

A estagiária refere à criança "olha, eu vou fazer com que tu entendas!” $\mathrm{E}$ procura colocar a criança devidamente no círculo, ao que ela resiste. Consegue levantá-la e vai colocá-la numa cadeira perto da educadora. Volta para o círculo e continua com as restantes crianças no planeamento. Quando termina com estas, fala discretamente com a criança antes de ir para o seu tempo de trabalho.

Tal como se ilustra na tabela 2, no contexto de participação, a estagiária recorre a três estratégias de forma consistente, para estabelecer os limites: o apelo à reciprocidade, a evocação das regras e a possibilidade de regulação autónoma, relembrando os tempos presentes na rotina diária para influenciar o comportamento das crianças.

A estagiária não só opera na linha moral de cooperação (Piaget, 1984), como evidencia a relação de reciprocidade na igualdade de direitos e responsabilidades. Neste sentido, o desenvolvimento da relação criança-estagiária é caracterizada pela partilha do poder, fundamental para a transição da heteronomia para a autonomia moral (DeVries \& Zan, 1998; OliveiraFormosinho \& Araújo, 2008).

Acresce referir a existência, nesta sala, de quadros individuais e elaborados pelas crianças face às regras acordadas conjuntamente.

Quando as crianças se envolvem em experiências de aprendizagem com partilha de poder crescem na sua capacidade de se entenderem a si próprias e de se relacionarem adequadamente com os outros, sendo evidente a reciprocidade e o respeito mútuo (DeVries \& Zan, 1998; Lino, 1996).

Tabela 2.

Exemplos de estratégias utilizadas pela estagiária em contexto de pedagogia de participação.

\begin{tabular}{lc}
\hline Ilustração & Fonte \\
\hline No tempo da revisão, a criança que está do & \\
lado direito da estagiária, brinca com os \\
materiais que estão perto de si. A estagiária \\
envolve-a pelas costas com as mãos e \\
discretamente, faz rodar o seu corpo para a \\
mesa. A criança acede, mas logo em \\
\hline
\end{tabular}


seguida, volta-se de novo. A estagiária tolera o seu comportamento, limitando-se, de vez em quando, a olhares fugazes.

No decurso do tempo da revisão, apoiada pela estagiária, uma criança interrompe a sua revisão e diz "Assim não pode ser, vocês não estão a ouvir e eu não posso continuar”. Após o silêncio das duas colegas, esta agradeceu e continuou a revisão.

"Na realidade educativa onde estagiei, tudo
é planeado, para que a intervenção seja
positiva e haja um clima de apoio (...) A
criança é ouvida, as suas ideias são
valorizadas e respeitadas” (p.19)
"Foi no sentimento de partilha de poder que
se baseou a minha postura perante o grupo Portefólio
de crianças “ (p.29)
"procurei ter um posicionamento, tanto
físico como verbal, que facilitasse a relação
com elas, demonstrei desta forma a minha
total disponibilidade para as ouvir” (p.23)

A estagiária vira-se para as duas crianças que conversavam entre si e refere:"'Olhem, quando vocês fizeram a revisão e o João estava atento. Ele ouviu a vossa revisão. Agora é a vossa vez que ouvi-lo”.

No planeamento a estagiária diz: “Olha, espera aí. Espera António. O António estava a fazer o seu plano, mas eu ouvi pouco porque os meninos estavam todos a falar. Que regras, é que nós temos em relação a isto?" "Para não falar" - responde uma criança. "Para falar um de cada vez" acrescenta outra. "Então, vamos ouvir o resto do plano do António?”, diz a estagiária.

\section{Considerações finais}

Os resultados obtidos foram inequívocos, destacandose o uso de diferentes estratégias de gestão do comportamento das crianças pelas candidatas a educadoras de Infância.

A estagiária no contexto de pedagogia de transmissão recorre à punição como instrumento regulatório quando confrontada com o comportamento inadequado da criança, sendo orientada para uma gestão coercitiva. Por sua vez, na sala de pedagogia de participação verifica-se um equilibrio entre o poder da criança e o da educadoraestagiária. A educadora-estagiária funciona como um modelo prosocial face à criança, apelando sobretudo à reciprocidade e às regras que foram co-construídas como um instrumento colaborativo de socioregulação e autoregulação das interações na sala como ponto de referência para refletir e dialogar e não para punir. Com efeito, os dados salientam que a conquista de uma "gramática pedagógica" se constitui como a fonte de aprendizagem integrada para os atores considerados: estagiária e criança.

Os resultados deste estudo indicam que a aprendizagem profissional é contextual, o que, em outras palavras, significa que estagiárias e contextos são realidades indissociáveis, havendo interdependência e interatividade entre as aprendizagens das candidatas a educadoras e os contextos supervisivos. Salienta-se igualmente uma diferenciação na iniciação das crianças às formas como as figuras de autoridade exercem o seu poder.

Os dados apresentados demonstram a absoluta necessidade de se melhorar a qualidade dos contextos supervisivos, bem como de repensar e redimensionar a importância conferida institucionalmente ao papel da supervisora cooperante e, consequentemente, ao tipo de formação contínua de que dispõe no âmbito da pedagogia da infância como sustentação primordial da transformação do quotidiano.

\section{Referencias bibliográficas}

Alarcão, L., \& Canha, B. (2013). Supervisão e colaboração: Uma relação para o desenvolvimento. Porto: Porto Editora.

Bogdan, R., \& Biklen, S. (1994). Investigação Qualitativa em Educação - uma introdução à teoria e aos métodos. Porto: Porto Editora.

Craveiro, C. (2007). Formação em Contexto: um estudo de caso no âmbito da pedagogia da infância. Dissertação de Doutoramento. Instituto de Estudos da Criança, Universidade do Minho, Braga.

DeVries, R., \& Zan, B. (1998). A ética na educação infantil - o ambiente sociomoral na escola. Porto Alegre: Artmed.

Dewey, J. (1971). Experiência e Educação. São Paulo: Companhia Editora Nacional.

Edwards, C., Gandini, L., \& Forman, G. (1999). As Cem Linguagens da Criança: a abordagem de Reggio Emília na educação da primeira infância. Porto Alegre: Artmed.

Formosinho, J. (2002). A Academização da Formação dos Professores de Crianças. Infância e Educação, Investigação e Práticas, 4, 19-35.

Formosinho, J., \& Oliveira-Formosinho, J. (2008). Pedagogy-in-Participation: Childhood Association's Approach. Lisbon: Research Report, Aga Khan Foundation.

Hoyuelos, A. (2004). La ética en el pensamiento y obra pedagógica de Loris Malaguzzi. Barcelona: Ediciones Octaedro.

Lino, D. (1996). A Intervenção Educacional para a Resolução de Conflitos Interpessoais - Relato de uma experiência de formação da equipa educativa. In J. O.-. Formosinho (Ed.), Educação Pré-Escolar - a construção social da moralidade (pp. 75-109). Porto: Texto Editora.

Lourenço, O. M. (2002). Desenvolvimento sócio-moral. Lisboa: Universidade Aberta.

Malaguzzi, L. (1993). For an education based in relationships. Young Children, 11, 9-13. 
Niza, S. (2007). O Modelo Curricular de Educação PréEscolar da Escola Moderna Portuguesa. In J. OliveiraFormosinho (Ed.), Modelos Curriculares para a Educação de Infância - Construindo uma praxis de participação (pp. 123-142). Porto: Porto Editora.

Nóvoa, A. (1992). Formação de Professores e Profissão Docente. In A. Nóvoa (Ed.), Os Professores e a sua Formação (pp. 17-33). Lisboa: Publicações Dom Quixote.

Oliveira-Formosinho, J. (1998). O desenvolvimento profissional das educadoras de infância: Um estudo de caso. Dissertação de Doutoramento. Instituto de Estudos da Criança, Universidade do Minho, Braga.

Oliveira-Formosinho, J. (2002). A supervisão pedagógica da formação inicial de professores no âmbito de uma comunidade de práticas. Infância $e$ Educação, Investigação e Práticas, 4, 42-68.

Oliveira-Formosinho, J. (2005). Da formação dos supervisores cooperantes à formação dos futuros professores de crianças - o ciclo de homologia formativa. In C. Guimarães (Ed.), Perspectivas para Educação Infantil (pp. 3-31). São Paulo: Junqueira e Marin Editores.

Oliveira-Formosinho, J. (2007). Pedagogias(s) da Infância: Reconstruindo uma Práxis de Participação. In J. Oliveira-Formosinho, T. Kishimoto \& M. Pinazza (Eds.), Pedagogia(s) da Infância: Dialogando com o assado Construindo o Futuro (pp. 13-35). São Paulo: Artmed.

Oliveira-Formosinho, J., \& Araújo, S. (2004). Children’s perspectives about pedagogical interactions. European Early Childhood Education Research Journal, 12(1), 103-114.

Oliveira-Formosinho, J., \& Araújo, S. (2008). A construção social da moralidade: a voz das crianças. In J. Oliveira-Formosinho (Ed.), A Escola Vista pelas Crianças (pp. 31-54). Porto: Porto Editora.

Serrano, G. (2000). Investigación cualitativa. Retos e Interrogantes II - Técnicas y análisis de datos. Madrid: La Muralla.
Shon, D. (1983). The reflective practitioner. New York: Basic Books.

Shonkoff, J. P., \& Meiseils, S. J. (2000). Handbook of early childhood intervention. Cambridge: Cambridge University Press.

Spodek, B. (2002). Manual de Investigação em Educação de Infância. Lisboa: Fundação Calouste Gulbenkian.

Stake, R. E. (2009). A Arte de Investigação com Estudos de Caso. Lisboa: Fundação Calouste Gulbenkian.

Parente, C. (2004). A Construção de Práticas Alternativas de Avaliação na Pedagogia da Infância: sete jornadas de aprendizagem. Dissertação de Doutoramento. Instituto de Estudos da Criança, Universidade do Minho, Braga.

Piaget, J. (1984). El criterio moral en el niño. Barcelona: Ediciones Martinez Roca.

Schweinhart, J., Montie, J., Xiang, Z., Barnett, W., Belfield, C., \& Nores, M. (2005). Lifetime effets: The High-Scope Perry Preschool study through age 40. Ypsilanti: High-Scope Press.

Sylva, K., Melhuish, E., Sammons, P., Siraj-Blatchford, I., \& Taggarat, B. (2004). The Effective Provision of Pre-School Education (EPPE) Project: Findings from the Early Primary Years. SureStart: Evidence \& Research.

Vieira, F., \& Lino, D. (2007). As contribuições da teoria de Piaget para a pedagogia da infância. In J. OliveiraFormosinho, T. Kishimoto \& M. Pinazza (Eds.), Pedagogia(s) da Infância: Dialogando com o passado, construindo o futuro (pp. 197-218.). São Paulo: Artmed.

Yin, R. (2003). Estudo de caso - Planejamento e Métodos. Porto Alegre: Artmed.

Zeichner, K. (1993). A formação reflexiva de professores: Ideias e práticas. Lisboa: Educa. 